\title{
Dental practice redecorates with music paintings for patient wellbeing
}

As of this October, clients at the Llanishen Dental Centre in Cardiff will be treated to a visual feast while they wait for treatment. The walls are now filled with music paintings. Each painting depicts one square metre of abstract explosions of shape, pattern and colour, created to distract and make people feel good.

Practice owners Rhys Loxton and David Morgan, knowing that there is increasing scientific evidence of art having measurable positive effects on health, invited local artist Shaun Ray, a champion of art, health and wellbeing, to put on a rolling exhibition of his work and make the experience of visiting the dentist refreshingly new.

Dr Loxton said: 'I want our clients to always have the very best and as we come out of COVID restrictions, these paintings really brighten up the environment; they're wonderful'.

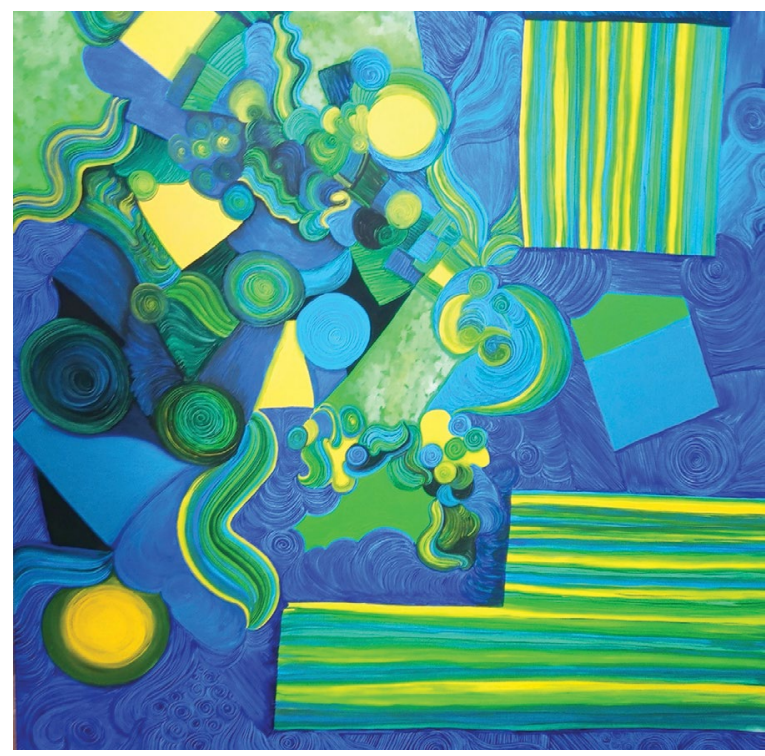

Examples of Shaun Ray's music paintings (c) Shaun Ray
Artist Shaun Ray has, until recently, run workshops for older members of the community, but COVID lockdown stopped all that and sent him back into his studio, where he, like so many artists, has been afforded the luxury of time to create.

Shaun said: 'I'm so happy that my work can be seen in a health setting. Art should be seen more in real places, not just in galleries and museums'.

Staff at the dental centre have also benefitted from the colourful new artwork. A dental technician said: 'On the first day it was a pleasure to be able to have a different conversation with clients. People really like [the art work] and it's great that a local artist gets a chance to show off his work'.

www.shaunray.wixsite.com/musicpainting

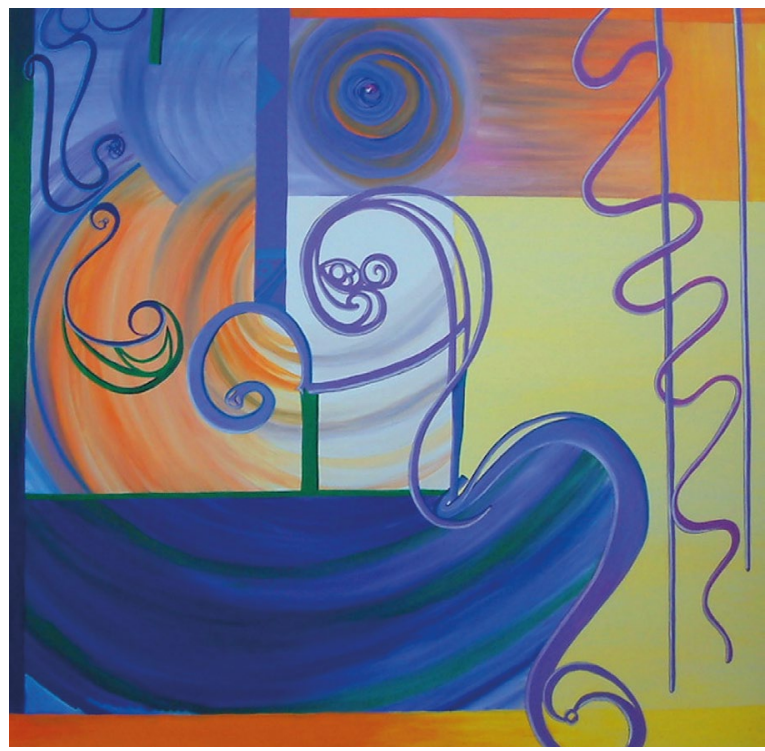

\section{Delivering better oral health on the go}

\section{By J. E. Gallagher and J. Godson}

Version 4 of Delivering better oral health: the evidence-based toolkit for prevention $(\mathrm{DBOH})$ has just been published on gov.uk. ${ }^{1}$ This guidance provides information and support to all members of the dental team from primary, secondary and tertiary care on how to improve their patients' oral and general health. This represents a collaborative effort from over 100 experts across the UK including frontline clinicians and academics, as well as patients and policymakers.

Key points to note about the new guidance:

- Available in digital format on gov.uk

- Summary guidance tables by disease, in Chapter 2

- Greater emphasis on supporting behaviour change, in Chapter 3

- Contains diseases-based guidance on dental caries, periodontal diseases, oral cancer and tooth wear and their major/minor risk factors (Chapters 4-7)

- New tables on the early identification of oral cancer and prevention of tooth wear are included

- Risk factor evidence on a healthier diet, fluoride, oral hygiene, tobacco and alcohol (Chapters 8-12)
- Risk assessment is considered in Chapter 1

- Resources for the dental team are only a click away at the end of each chapter.

Thanks to everyone across the UK who has worked hard behind the scenes to bring this together and for the support of Cochrane Oral Health and the Scottish Dental Clinical Effectiveness Programme (SDCEP). $\mathrm{DBOH}$ has been endorsed by a growing number of organisations and specialist societies including the British Dental Association. It has been a challenging time for dentistry throughout the pandemic and, as services recover, work is underway to see how best to support the implementation of $\mathrm{DBOH}$.

\section{References}

1. Public Health England, Department of Health and Social Care, NHS England, NHS Improvement. Delivering better oral health: an evidence-based toolkit for prevention. Updated 21 September 2021. Available at: https://www.gov.uk/government/ publications/delivering-better-oral-health-an-evidence-based-toolkit-forprevention (accessed October 2021). 